\title{
A Cost Model for
}

\section{Storage and Weeding Programs}

As space and budget problems become more severe, more academic libraries will be forced to consider storage and weeding as alternatives to new construction. Storage and weeding save space, but impose costs that may offset the potential savings. The simple mathematical model presented in this paper was developed to analyze the complex cost trade-offs involved. An example of the model's application in the University of California libraries is included. The limitations of the model and the importance of considering noneconomic factors in storage and weeding programs are discussed.

\begin{abstract}
A LTHOUGH LIBRARIES are always "running out of space," this problem began to take on considerable importance during the 1970s, when budgetary austerity curtailed the library construction boom of the previous decade. By 1975, the space issue was of sufficient importance that the American $\mathrm{Li}$ brary Association's Library Administration Division sponsored a preconference session at its Annual Conference titled "Running Out of Space-What Are the Alternatives?"1

As the title of this preconference implied, libraries were and are facing a number of alternatives for coping with their space problems. According to the conference organizers, these include storage, microforms, high-density shelving equipment, regional cooperation, and new construction, including addition and renovation. Among these alternatives, microforms are surely the least appealing for the individual library. Studies have shown that purchasing commercial microform may be costeffective, but the amount of commercially available material that could replace the books and journals on the shelves of large
\end{abstract}

Gary S. Lawrence is senior administrative analyst in the Library Studies and Research Division, Office of the Assistant Vice-President-Library Plans and Policies, University of California Systemwide Administration, Berkeley, California. academic libraries is rather small. Original microfilming of bound volumes appears to be more expensive than building new libraries to house the paper copies. ${ }^{2}$ For libraries facing the space problem today, then, the principal alternatives appear to be storage, weeding, and new construction.

Certainly the last alternative, new construction, is seen as the most desirable by most librarians and library users. Unfortunately, "running out of space" is perceived as a problem precisely because unlimited construction of new buildings is not believed to be economically possible at the present time or in the foreseeable future. The principal problem is economic. If libraries had enough money to build the new facilities they need, there would be no books and articles and conferences on alternatives to new construction-there would be no "space problem."

It follows that if the problem is primarily economic, the decisions we make in coping with the problem, and the justifications for those decisions, should be based on (although not limited to) economic considerations.

\section{Cost Trade-OFFs in \\ STORAGE AND WEEDING DECISIONS}

The choice to retain, store, or weed involves analysis of cost trade-offs. Ellsworth 
has observed, for instance, that compact storage systems "can store more volumes per square foot of space than traditional multi-tier bookstacks," but "there are costs associated with storage programs that may be greater than are the savings made by the storage systems themselves." 3

Cost trade-offs in storage and weeding decisions are analogous to those in the choice between continuing to subscribe to a particular periodical or canceling the subscription and relying on interlibrary borrowing to satisfy future demand. Palmour states that:

To maintain a periodical in its own collection, the library must select, order, process, store and make the publication available. For a requested item in a publication not in its own collection, there is the staff cost to locate and borrow the item; and in many cases, a photocopy charge. The cost to satisfy a request by borrowing is roughly the same each time, whereas the average cost per circulation of a publication acquired for the library collection is a function of how frequently it is circulated. Consequently, for any given periodical title there is some frequency of use at which it becomes cheaper for a library to acquire the publication than to borrow it to satisfy patron demand. 4

The solution to the storage and weeding problem can be expressed in similar terms: for any given volume in the library collection, there is some frequency of circulation at which it becomes cheaper not to house the publication in a conventional campus library. The ability to determine this frequency of circulation can be an important aid to planning, budgeting, and negotiating the solution to a library's space problem.

This paper presents a simple mathematical model that accounts for several of the complex cost trade-offs inherent in storage and weeding decisions, and provides an example of the application of this model in the University of California libraries.

\section{THE CosT MODEL}

Inasmuch as the problem of maintaining or canceling periodical subscriptions is somewhat similar to the problem at hand, it is not surprising that a cost model developed to analyze the subscriptions problem is, with minor modifications, admirably suited to analysis of the storage and weeding problem.
The cost model developed by Palmour and others was designed to determine the total discounted cost, over a specified planning period, attributable to the ownership and use of a single periodical title. ${ }^{5}$ Thus, the Palmour model included such elements as the annual subscription price, annual staff costs related to check-in and claiming, mechanisms to estimate varying use rates for all the extant and future volumes of the title, the increasing space requirements of the title over time, and other factors relevant to the analysis of serial publications at the title level.

Because the present study concerns individual volumes (both monographs and periodicals) rather than runs of periodical titles, it has proven possible to simplify the Palmour model greatly and to represent it in a linear form that can be used without reliance on a computer. The resulting cost equation has four principal components: (1) a "net present value factor" for discounting expenditures occurring in the future; (2) the cost of building and maintaining a library facility, expressed in dollars per volume; (3) the cost to select and process a volume for storage or weeding; and (4) the direct cost for one circulation of a volume, including transportation and communication costs and lending fees. The derivation of this cost model is explained in detail in the appendix.

The simplified cost model is shown in equation 1.

$$
U_{t}=\frac{C_{u} r_{t}}{t}+\frac{C_{w}+C_{v} r_{t}}{t} Y
$$

where:

$U_{t}=$ the total cost per circulation, expressed as a present value when capital costs are amortized over planning period $t$.

$Y=$ the expected average number of years between circulations.

$r_{t}=$ the net present value factor for a discount rate $r$ over planning period $t$

$$
\left(r_{t}=\sum_{n=1}^{t-1} \frac{1}{1+r^{n}}=\frac{(1+r)^{t-1}-1}{r(1+r)^{t-1}}\right.
$$

by a standard formula).

$C_{v}=$ the annual cost of housing the volume.

$C_{w}^{v}=$ the one-time cost to select the volume for weeding or relegation to compact shelving.

$C_{u}=$ the direct cost per circulation. 


\section{APPLYING THE MODEL: AN ExAMPLE}

We can demonstrate the application of the cost model using estimates drawn from published studies and various budget and planning documents produced within the University of California to support development of the university's storage program. ${ }^{6}$ Costs used here are adjusted to 1978 dollars using the GNP deflator.

\section{Discount Rate and Planning Period}

The value of $r_{t}$ in equation 1 is derived from $r$, the interest rate, and $t$, the planning period. Several values for the interest rate are defensible in theory, but in practice the rate for AAA corporate bonds is most frequently used. This rate was fluctuating around 8 percent in 1978 , and $r=0.08$ is used throughout this analysis. The value of $t$ is the "useful life" of the object in question, in this case the library or storage facility. We have used a period of forty years, which is a frequently cited depreciation period for nonresidential buildings. When $r=0.08$ and $t=40$, the value of $r_{t}$ is 11.88. Substituting the values of $t$ and $r_{t}$ in equation 1 yields equation 2 .

$$
U_{t}=\frac{11.88 C_{u}}{40}+\frac{C_{w}+11.88 C_{v}}{40} Y
$$

\section{Campus Retention}

The annual cost of housing material $\left(C_{v}\right)$ in a conventional library has two components: the annualized capital cost of construction and equipment, and the annual recurring cost of maintaining the facility. The average cost per volume to construct and equip a campus library in California in 1978 has been estimated at about $\$ 10.13$ per volume. The annual value of the initial capital expenditure is calculated using the standard formula: ${ }^{7}$

$$
A=P\left(\frac{i}{(1+i)^{n}-1}+i\right)
$$

where:

$i=$ interest rate per period.

$n=$ number of periods.

$P=$ the present sum of money, or initial investment.

$A=$ the end-of-period payment in a uniform series for $n$ periods, the entire series equivalent to $P$ at interest $i$.
The annualized cost of a $\$ 10.13$ capital expenditure over forty years at 8 percent is $\$ 0.85$ per year. The annual cost of maintenance has been estimated by the university to be about $\$ 0.24$ per volume per year. $C_{v}$ is then $\$ 0.85+\$ 0.24$, or $\$ 1.09$ per year.

The cost of each circulation $\left(C_{u}\right)$ includes record keeping, charging and discharging a volume, and reshelving it. Using budget and circulation data from the UC libraries, the average cost per circulation in 1978/79 dollars was about $\$ 0.92$. For materials retained on campus there are no selection costs (or more precisely, the costs of a selection program are assigned entirely to the items finally chosen for storage or weeding). Substituting these estimates in equation 2, the cost per circulation for materials retained on campus is shown in equation 3.

$$
\begin{aligned}
U_{t}^{c} & =\frac{11.88(.92)}{40}+\frac{0+11.88(1.09)}{40} Y \\
& =.2732+.3237 Y
\end{aligned}
$$

\section{Relegation to Storage}

The housing cost $\left(C_{v}\right)$ for storage facilities has two components analogous to those of on-campus housing: the annualized capital cost of building and equipping the facility, and the annual recurring maintenance cost.

Preliminary estimates made in 1978 for the University of California's regional storage program suggested that the cost of constructing and equipping such facilities would be about $\$ 2.33$ per volume. Annualized over forty years at 8 pecent, this amounts to $\$ 0.20$ per year. With maintenance and utilities costs, $C_{v}$ is about $\$ 0.44$ per volume per year.

The cost of selection $\left(C_{w}\right)$ includes identification, transportation, shelving, and record changing. Estimates of the cost to identify items for storage and weeding range from $\$ 0.70$ per volume considered for discard $^{8}$ to $\$ 2$ per volume selected. ${ }^{9} \mathrm{Be}$ cause the decision to send a book to storage is reversible (i.e., the volume can always be returned to the campus collection), we have assumed that an inexpensive selection procedure is acceptable, and used the lower figure of $\$ 0.70$ per volume examined. Assuming that 90 percent of the books examined are chosen for storage, the cost is 
$\$ 0.78$ per volume selected. Adding the estimated cost of changing bibliographic records, $\$ 1$ per volume, gives a total of $\$ 1.78$, or $\$ 1.93$ in 1978 dollars. ${ }^{10}$ Book transportation and initial shelving may add about $\$ 0.70$, for a total of $\$ 2.63$ per volume.

The unit cost of circulation $\left(C_{u}\right)$ from storage facilities includes retrieval, transportation, communication, and reshelving. These are all costs incurred by the library. An additional cost is borne by the patronthe cost of the time delay inherent in retrieving materials from an off-campus facility.

Estimates of expected circulation rates and staff costs for the proposed UC regional facilities suggest a unit cost of about $\$ 1.66$ per transaction. The "cost" to users of an expected two-day delay in delivery from the regional facilities ${ }^{11}$ has been estimated from two sources, a published study of the relative utility of timeliness in the delivery of library services ${ }^{12}$ and a University of California study of the willingness of users to pay for forty-eight-hour interlibrary borrowing service. ${ }^{13}$ On the basis of these studies, we estimated that users would, on the average, be willing to pay $\$ 2.12$ to avoid the forty-eight-hour delay in delivery of materials housed in the UC storage facilities.

To the direct cost of circulation (\$1.66) and the cost of delay (\$2.12), we add the cost of round-trip transportation, estimated at $\$ 1.50$ per circulation, to arrive at the total direct cost of a single circulation, $C_{u}=\$ 5.28$ per transaction. The total cost per circulation for materials relegated to storage is therefore as shown in equation 4 .

$$
\begin{aligned}
U_{t}^{s} & =\frac{11.88(5.28)}{40}+\frac{2.63+11.88(.44)}{40} Y \\
& =1.5682+.1964 Y
\end{aligned}
$$

\section{Removal from the Collection}

The cost of weeding $\left(C_{w}\right)$ is analogous to the selection of volumes for compact shelving, and includes review, record changing, and disposing of the volumes. Assuming that a library would adopt the most rigorous feasible review procedures for an irreversible decision to discard a volume, the highest cost estimate found in the literature, $\$ 2$ per volume selected, seems justified. ${ }^{14}$
Adding the cost of changing library records, the total is $\$ 3.73$ per volume in 1978 dollars.

The cost of circulation $\left(C_{u}\right)$ includes both internal and external costs incurred by the borrowing library. According to Palmour's study, requesting libraries spend about $\$ 7.20$ per transaction to process an interlibrary lending (ILL) request. ${ }^{15}$ In addition, the borrowing library may have to pay a fee to the lending library. Like Palmour, we have assumed that lending libraries charge $\$ 3$ per volume lent on ILL, for a total of $\$ 10.20$, or $\$ 11.04$ in 1978 . Using the procedures for estimating the cost of delay, discussed above, and assuming a two-week delay on ILL transactions, the cost of delay is $\$ 6.12$. Thus, the cost of a circulation $\left(C_{u}\right)$ is $\$ 17.16$. The total cost per circulation for materials removed from the collection, where circulation is provided through interlibrary borrowing, is shown in equation 5.

$$
\begin{aligned}
U_{t}^{w} & =\frac{11.88(17.16)}{40}+\frac{3.73+11.88(0)}{40} Y \\
& =5.0965+.0933 Y
\end{aligned}
$$

"Crossover Points" for

Compact Shelving and Disposal

Costs per circulation for selected values of $Y$ are presented in table 1 for each of the three cost functions. Figure 1 graphs the linear equations 3,4 , and 5 for values of $Y$ from one use per year to one use in forty years.

We will refer to the point at which the cost per circulation for two housing alterna-

\section{TABLE 1}

Estimated Present Value Cost per Circulation for Three Housing Options

\begin{tabular}{cccc}
\hline $\begin{array}{c}\text { Average Years } \\
\text { between } \\
\text { Circulations }(Y)\end{array}$ & $\begin{array}{c}\text { Present Value Cost per Circulation } \\
\text { Campus } \\
\text { Library }\end{array}$ & Storage & $\begin{array}{c}\text { Interlibrary } \\
\text { Borrowing }\end{array}$ \\
\hline 1 & 0.60 & 1.76 & 5.19 \\
2 & 0.92 & 1.96 & 5.28 \\
3 & 1.24 & 2.16 & 5.38 \\
4 & 1.57 & 2.35 & 5.47 \\
5 & 1.89 & 2.55 & 5.56 \\
10 & 3.51 & 3.53 & 6.03 \\
15 & 5.13 & 4.51 & 6.50 \\
20 & 6.75 & 5.50 & 6.96 \\
30 & 9.99 & 7.46 & 7.89 \\
40 & 13.22 & 9.43 & 8.83 \\
\hline
\end{tabular}




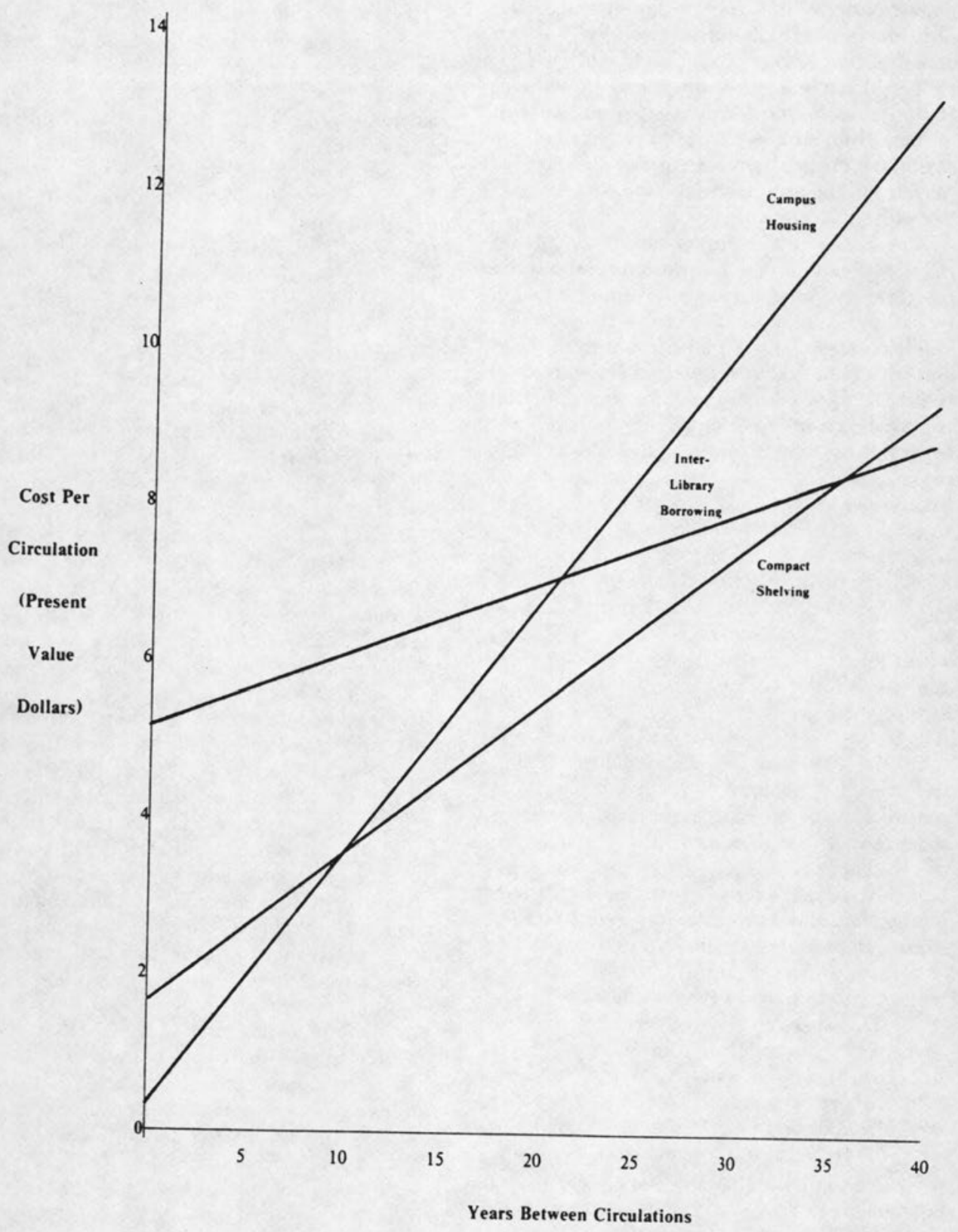

Fig. 1

Estimated Cost of Circulation for Three Housing Alternatives 
tives is equal as the crossover point for those options. In figure 1, for instance, the cost function for campus housing crosses the function for storage at about $Y=10$ years. When $Y$ is less than ten (i.e., books circulate more frequently than once in ten years), the cost per circulation is less for campus housing than for storage. When $Y$ is greater than ten, circulation costs are less for stored volumes.

Precise crossover points can be calculated from the cost functions presented above by setting the cost equations equal to each other and solving for $Y$. To find the campusto-disposal crossover point, for instance, we set the campus-cost function (equation 3) equal to the weeding-cost function (equation $5)$, as shown in equation 6.

$$
\begin{aligned}
.2732+.3237 Y & =5.0965+.0933 Y \\
(.3237-.0933) Y & =5.0965-.2732 \\
.2304 Y & =4.8233 \\
Y & =20.9345
\end{aligned}
$$

The precise crossover points resulting from these calculations are presented in table 2.

\begin{tabular}{|c|c|c|}
\hline From & Disposition & $\begin{array}{c}\text { Years between } \\
\text { Uses }(\boldsymbol{Y})\end{array}$ \\
\hline Campus & Disposal & 20.93 \\
\hline Campus & Storage & 10.17 \\
\hline Storage & Disposal & 34.22 \\
\hline
\end{tabular}

TABLE 2

Crossover Points for STORAGE AND DISPOSAL

On the basis of these estimates, we conclude that when there is no storage facility, items that are circulated once or more in twenty-one years should be retained on campus; when the circulation rate is less than once in twenty-one years, it is less expensive to discard the volume and rely on interlibrary borrowing to meet demand. When there is a storage facility, items that are circulated once or more in ten years should be retained on campus. Volumes with circulation rates between once in ten years and once in thirty-four years are more economically placed in storage. For volumes with circulation rates lower than once in thirty-four years, it is less expensive to dispose of them or place them in national repositories and satisfy demand for them through interlibrary borrowing.

\section{Discussion}

The cost model reported here is relatively simple and straightforward; obtaining correct cost figures to use in the model is not necessarily so easy. In using this model for cost analysis and interpreting the results, there are three sources of potential difficulty: accuracy of the cost estimates, acceptability of the assumptions, and capacity to apply the results.

The result of economic modeling can be no better than the data used in the model. Accuracy may be difficult to achieve, though, when the library is considering options with which it has no previous experience, and therefore must use estimates based on the experience of others. Sensitivity of the results to uncertain cost estimates can be important. For example, if the actual cost per item for transportation to storage is only $\$ 0.07$, rather than the estimate of $\$ 0.70$ used in the example discussed above, both selection and direct circulation costs are affected. The result of this change in an apparently minor cost factor is to shift the crossover point between campus housing and storage from one use in 10.17 years to one use in 6.25 years. ${ }^{16}$

The application illustrated here has also made use of a number of simplifying assumptions. The clearest example is the assumption that all uses and use-related costs can be accounted for by circulation. Ideally, the analysis should include all forms of use of material, including uses at tables and shelves within the library. Unfortunately, few libraries have information on the incidence of in-library use of their collections, or the capacity to account separately for the costs of in-house and circulated use.

Another important assumption is that demand for library materials is invariant with changes in delay times, distance, or convenience. The fact that materials are no longer in the campus collection may have an effect on user demand for them, even though they may still be available at storage facilities or through interlibrary borrowing. We have attempted to account for the problem in our analysis by including an estimate of the cost to users of the inconvenience of waiting for materials delivered from storage or through interlibrary borrowing, but it is 
likely that this adjustment does not fully account for the possible effect on library users of remote housing of library material.

When we speak here of weeding and reliance on interlibrary borrowing, we assume that a copy of the weeded item will be available in some other library when needed. In the absence of a national "lastcopy clearinghouse" that would assure availability of at least one copy of any publication, this assumption may be unwarranted. If we abandon the assumption, the cost of circulation for the disposal option must rise by some unknown factor to reflect costs imposed on users by the absolute unavailability of previously owned material. Depositing weeded items in a national repository like the Center for Research $\mathrm{Li}$ braries might solve this problem; the proposed National Periodicals Center is another possible solution. Accounting for these possibilities in the cost analysis adds considerable complexity and uncertainty (especially in the case of the NPC), but the inclusion of cooperative last-copy arrangements at the national or regional levels is an obvious direction for further development of this analytical technique.

This analysis also assumes that each volume in the library is an independent entity for the purpose of storage or weeding choices. Rigorous adherence to this assump- tion could result in breaking up a journal set in which only a few volumes are used frequently, which could be an injudicious decision. Separate treatment of monographs and periodicals, government documents, special collections, reserves, or other definable subcollections could be useful. Each such level of partitioning raises problems in securing book-use and cost data, but disaggregation of collections is another promising direction for further development of the analysis.

Finally, we take note of limitations in the capacity to apply the findings of the cost analysis. Having established a criterion of, say, one use in ten years as a criterion for relegation to storage, it is necessary to have some information about the past and current use of the collection in order to estimate the amount of material to be stored and to aid in selecting individual volumes. Such data are not readily available in most libraries and are not always easy to obtain.

Despite these limitations (some of which can perhaps be overcome by additional data collection and analysis), the cost model demonstrated here has proven to be a useful tool for assessing the feasibility of storage and weeding programs, and is capable of providing useful information for initial planning and budgeting of such programs when they are shown to be feasible.

\section{REFERENCES}

1. Gloria Novak, ed., Running Out of SpaceWhat Are the Alternatices? Proceedings of the Preconference, June 1975, San Francisco (Chicago: American Library Assn., 1978).

2. See, for example, University of California, Office of the Executive Director of Universitywide Library Planning, The University of California Libraries: A Plan for Development, 1978-1988 (Berkeley: Univ. of California, 1977), p. 161-66.

3. Ralph E. Ellsworth, The Economics of Book Storage in College and University Libraries (Metuchen, N. J.: Scarecrow, 1969), p.13.

4. Vernon E. Palmour, Marcia C. Bellassai, and Robert R. V. Wiederkehr, Costs of Owning, Borrowing, and Disposing of Periodical Publications (Arlington, Va.: Center for Naval Analyses, 1977), p.1.

5. Palmour, Costs of Owning, p.23-29.

6. For a description of the program, see University of California Libraries, chapter X.
7. This financial formula is found in a number of textbooks, including Eugene L. Grant and W. Grant Ireson, Principles of Engineering Economy (5th ed.; New York: Ronald, 1970).

8. Univeristy of California Libraries, p. 169.

9. George Piternik, Book Storage in Academic Libraries: A Report Submitted to the Council on Library Resources (Vancouver, B.C.: Univ. of British Columbia, School of Librarianship, 1974), p.7.

10. University of California Libraries, p.175.

11. The response-time standard of forty-eighthour delivery from regional storage is enunciated in University of California Libraries, p.51.

12. A. Reisman and others, "Timeliness of Library Materials Delivery: A Set of Priorities," Socio-Economic Planning Sciences 6:145-52 (1972).

13. Donald D. Thompson, "Interlibrary Lending and Intercampus Photocopy: A Study of User 
Demand and System Response among Northern University of California Campuses" (Berkeley: Univ. of California, General Library, Special Projects, June 25, 1975).

14. Piternik, Book Storage in Academic Libraries, p. 7 .

15. Palmour, Costs of Owning, p.46.

16. Details of this sensitivity analysis will be found in Gary S. Lawrence and Anna R. Oja, An Economic Criterion for Housing and Disposing of Library Materials, Based on Frequency of Circulation (Berkeley: Univ. of California Systemwide Administration, Office of the Assistant Vice-President-Library Plans and Policies, September 24, 1979), appendix $C$.

\section{APPENDIX}

The cost model developed by Palmour and others was designed to determine the total discounted cost, over a specified planning period, attributable to the ownership and use of a single periodical title. Most of the special features used in Palmour's model to account for multiple volumes are not necessary for the analysis of costs for a single volume already held by the library. The Palmour model has been modified to reflect these simplifying conditions.

The complete cost model developed by Palmour is shown in equation 1.

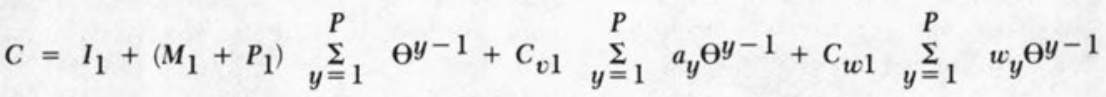

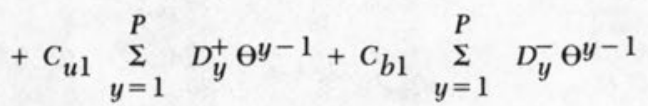

where:

$C=$ present value of all costs associated with owning, using, weeding, and/or borrowing the title.

$I_{1}=$ initial cost to acquire and catalog a new title.

$\vec{M}_{1}=$ recurring annual cost (check-in, claiming, binding, etc.); this cost is assumed to be constant for all years in the planning period.

$P_{1}=$ annual subscription cost; assumed to be constant for all years.

$y=$ the year index within the planning period, $y=1$ to $P$.

$P \quad=$ the length of the planning period in years.

$\theta=$ the net discount rate, defined as $\theta=\frac{1+i}{1+r}$, where $i$ is the inflation rate and $r$ is the discount rate, expressed as decimal fractions.

$C_{v 1}=$ cost of relegating an annual volume to remote compact shelving; assumed to be constant for all years in the planning period.

$a_{y}=$ the number of annual volumes of the title held in the library in year $y$.

$C_{w 1}=$ the cost of weeding a single volume; assumed to be constant.

$w_{y}=$ the number of volumes weeded in year $y$.

$C_{u 1}^{y}=$ the cost of satisfying a request for an annual volume held by the library.

$D_{y}^{+}=$number of satisfied requests for an annual volume held by the library in year $y$.

$C_{b 1}^{y}=$ cost of satisfying a request for an annual volume not held by the library (interlibrary borrowing cost).

$D_{y}^{-}=$number of satisfied requests for annual volumes not held by the library in year $y$.

The derivation and justification of this formula are presented in appendix A of the Palmour report.

In the present case, there are no initial cataloging costs, annual recurring costs, or subscription costs, and the first two elements of the Palmour model reduce to zero. In the third component of equation 1 (the annual cost of housing the volumes of the title) the variable $a_{y}$ (number of annual volumes held in year $y$ ) is always one in the present application, and the term reduces simply to $C_{v 1} \Sigma$ $\theta^{y-1}$

In the fourth component of equation 1 (the cost of selecting a volume for relegation or weeding), a volume is either weeded or it is not: $w_{y}$ always equals one or zero. The expense incurred in selecting a single volume occurs only once: if we assume that the decision is made at the beginning of the planning period, the present value term $\left(\Sigma \Theta^{y-1}\right)$ can be eliminated, and the cost of selection represented simply as $C_{w 1}$; the variable has the value of zero when no selection process is involved. So far, then, the modified model is represented by equation 2 . 


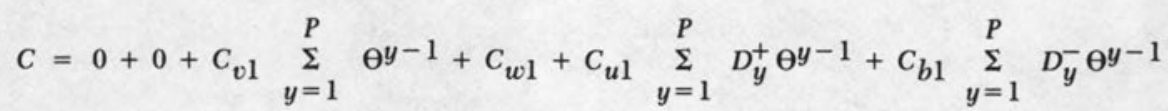

The last two components of the model deal with the costs of use of a title. Palmour needed two use-cost elements-internal use and interlibrary borrowing-because the library may incur internal costs for use of existing back files, as well as interlibrary borrowing costs for "future" volumes that are not purchased. For this analysis, the volume is either in the collection or it is not, and one cost component is sufficient.

The Palmour model must accommodate differing circulation rates for the title as a whole in successive years, to reflect the simultaneous effects of growth of the back file and declining circulation rates for older volumes, an unnecessary feature for the single-volume case. If the annual circulation rate of the volume is assumed to be constant over time, the rate-of-circulation parameter $\left(D_{y^{\prime}}^{+} D_{y}^{-}\right)$can be moved outside the summation sign. The reduced version of the circulation-cost component is $C_{u 1} D \Sigma$ $\Theta^{y-1}$, where $C_{u l}$ is the cost of a circulation for the alternative under consideration and $D$ is the average annual circulation rate. The cost equation is now equation 3 .

$$
C=C_{v 1} \underset{y=1}{\sum_{y}} \theta^{y-1}+C_{w 1}+C_{u 1} D \underset{y=1}{P} \theta^{y-1}
$$

The summation operation on theta, appearing in two components, is constant for any given values of $P$ and $\Theta$. For convenience, we shall designate the value of $\Sigma \Theta^{y-1}$ as $r_{t}$ for a given discount rate $r$, when $P$ equals some value $t$. We can eliminate some unnecessary subscripts and express the model as shown in equation 4.

$$
C=C_{v} r_{t}+C_{w}+C_{u} D r_{t}
$$

Equation 4 represents the total cost of housing and circulating a volume with an annual use rate of $D$ for a period of $t$ years. It is convenient to express the result of the cost equation in terms of cost per circulation. If $D$ is the average annual circulation rate, the total number of circulations in period $t$ is $D t$ and the cost per circulation is $\frac{C}{D t}$. Dividing through the model by $D t$ gives:

$$
\begin{aligned}
\frac{C}{D t} & =\frac{C_{v} r_{t}+C_{w}+C_{u} D r_{t}}{D t} \\
& =\frac{C_{w}+C_{v} r_{t}}{D t}+\frac{C_{u} r_{t}}{t} \\
& =\frac{C_{u} r_{t}}{t}+\frac{C_{w}+C_{v} r_{t}}{t} \frac{1}{D}
\end{aligned}
$$

The inverse of the circulation rate $\left(\frac{1}{D}\right)$ is simply the number of years between circulations. Representing this component as $Y$, we have the simplified model used in this report:

$$
U=\frac{C_{u} r_{t}}{t}+\frac{C_{w}+C_{v} r_{t}}{t} Y
$$




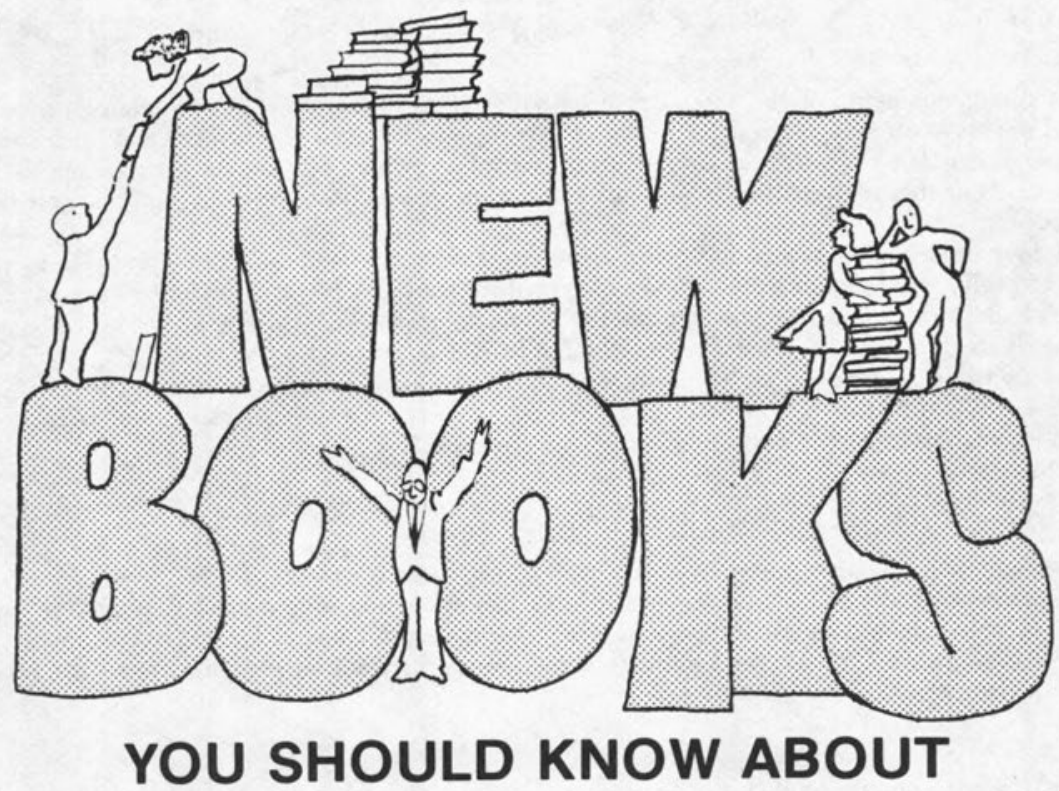

BASIC LINEAR ALGEBRA WITH APPLICATIONS (1980)

Garfield C. Schmidt

INTRODUCTION TO VECTOR STOCHASTIC PROCESSES (1980) Kenneth S. Miller

HYPOTHESIS TESTING WITH COMPLEX DISTRIBUTIONS (1980) Kenneth S. Miller

\section{GENERAL PROBLEM OF} APPROXIMATION AND SPLINE FUNCTIONS (1979) A.S.B. Holland \& B.N. Sahney ORDINARY DIFFERENTIAL EQUATIONS, 2nd Ed. (1980) Jack K. Hale
MECHANICS OF CONTINUA, 2nd Ed. (1980)

A. Cemal Eringen

INTERMEDIATE ECONOMIC STATISTICS, 2nd Ed. (1980) Karl A. Fox \& Tej K. Kaul

HANDBOOK OF EFFECTIVE GRAPHIC \& TABULAR

COMMUNICATION (1980) AND

MANAGEMENT HANDBOOK OF DECISION-ORIENTED STATISTICS (1980) Norbert L. Enrick

MASER AND LASER ENGINEERING (1980) T. Koryu Ishii
PHYSICAL BASIS OF MUSICAL SOUNDS (1980) Joseph Morgan

ADHESIVES, ADHERENDS, ADHESION (1980)

Nicholas J. DeLollis

ERROR-FREE COMPUTATION (1980) Robert T. Gregory

ELECTRONIC STRUCTURE AND TRANSPORT PROPERTIES OF CRYSTALS (1980) W.F. Leonard \& T.L. Martin

FLUID POWER FOR INDUSTRIAL USE (2 Vols.) (1981)

Olat A. Johnson

Complete price information available on request.

\section{Our New Address}

Please change your records.

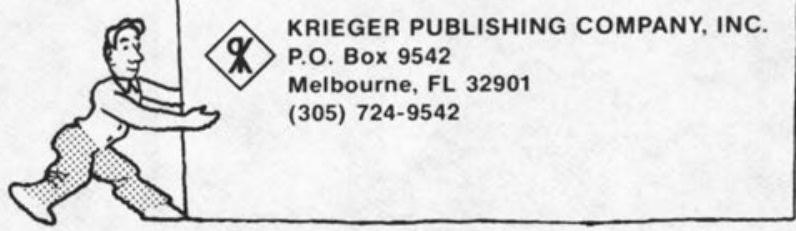

